\title{
Neonatal volume guarantee ventilation: effects of spontaneous breathing, triggered and untriggered inflations
}

\author{
N McCallion, ${ }^{1,4}$ R Lau, ${ }^{1}$ C J Morley, ${ }^{1,2,3}$ P A Dargaville ${ }^{2,3}$
}

${ }^{1}$ Neonatal Services, Royal Women's Hospital, Melbourne, Victoria, Australia; ${ }^{2}$ Department of Neonatology, Royal Hobart Hospital, Tasmania, Australia;

${ }^{3}$ Murdoch Children's Research Institute, Melbourne, Victoria, Australia; ${ }^{4}$ Neonatal Intensive Care Unit, National Maternity Hospital, Dublin, Ireland

Correspondence to: Dr N McCallion, Neonatal Intensive Care Unit, National

Maternity Hospital, Holles St,

Dublin 2, Ireland; n.mccallion@ bristol.ac.uk

Accepted 26 July 2007 Published Online First

8 August 2007

\begin{abstract}
Background: During volume guarantee (VG) ventilation the peak inflating pressure (PIP) for each ventilator inflation is adjusted to ensure the expired tidal volume $\left(V_{T e}\right)$ is close to the set $V_{T e}$. Differences in the PIP between inflations triggered by the infant's inspirations and untriggered inflations are seen.

Aim: To investigate the effects of triggered and untriggered inflations on PIP and $\mathrm{V}_{\mathrm{Te}}$.

Methods: Neonates were ventilated with the Dräger Babylog 8000 using assist control (synchronous intermittent positive pressure ventilation) and VG modes. Continuous recordings of ventilator pressures and tidal volumes were made at $200 \mathrm{~Hz}$ for 10 minutes.
\end{abstract}

Results: In 10 infants, 6540 inflations were analysed, of which 4052 (62\%) were triggered. Triggered inflations had a significantly lower mean (SD) PIP than untriggered inflations: 12.9 (4.9) vs 17.0 (3.3) $\mathrm{cm} \mathrm{H}_{2} \mathrm{O},(p<0.001$ ). Despite this, there was no significant difference in the $\mathrm{V}_{\mathrm{Te}}$ of each type of inflation $1103 \%$ and $101 \%$ of the set $V_{T e}$, respectively). When a triggered inflation was immediately preceded or followed by an untriggered inflation the PIP changed by about $5 \mathrm{~cm} \mathrm{H} \mathrm{H}_{2} \mathrm{O}$. Between adjacent inflations of the same type, the change in PIP was less than $3 \mathrm{~cm}$ $\mathrm{H}_{2} \mathrm{O}$ : for triggered inflations it was $0.11(1.50) \mathrm{cm} \mathrm{H}_{2} \mathrm{O}$ and for untriggered inflations 0.06 (1.53) $\mathrm{cm} \mathrm{H}_{2} \mathrm{O}$.

Conclusion: During VG ventilation with the Dräger Babylog 8000 the PIP was $4 \mathrm{~cm} \mathrm{H}_{2} \mathrm{O}$ lower during triggered inflations than untriggered inflations, although the expired tidal volumes were similar.

Increased awareness of the role of volutrauma, and lung overdistension in the pathogenesis of ventilator-induced lung injury in animal models and adults has led to the development of volumetargeted modes of ventilation for neonates. ${ }^{1-8}$ The pressure required to inflate the lungs of very preterm infants varies considerably owing to changes in their lung disease, the size of their spontaneous breaths, surfactant treatment, the use of uncuffed endotracheal tubes with a variable leak and different ventilation strategies. Volume guarantee (VG) ventilation aims at ensuring a consistent expiratory tidal volume by varying the peak inflating pressure (PIP) for each inflation.

VG is a time-cycled, pressure-limited, mode of ventilation on the Dräger Babylog 8000 plus (Dräger Medical, Lübeck, Germany). It measures each expired tidal volume $\left(\mathrm{V}_{\mathrm{Te}}\right)$ and alters the PIP for the next inflation to try to maintain the $\mathrm{V}_{\mathrm{Te}}$ at a level that has been set by the operator. When the $\mathrm{V}_{\mathrm{Te}}$ delivered is less than the set $\mathrm{V}_{\mathrm{Te}}$ the ventilator increases the PIP for the next inflation. If the $\mathrm{V}_{T e}$ is larger than the set $\mathrm{V}_{\mathrm{Te}}$ the PIP is reduced for the next inflation. According to the manufacturer's information each change in PIP does not exceed $3 \mathrm{~cm} \mathrm{H}_{2} \mathrm{O}$. To compensate for variability in the infant's respiratory effort, lung compliance and leaks around the endotracheal tube, the ventilator continuously modulates the PIP to control the $\mathrm{V}_{T e}$. Therefore the VG mode delivers a mean $V_{T e}$ very close to the set $\mathrm{V}_{\mathrm{Te}}$. $^{\text {79-12 }}$

At the Royal Women's Hospital, Melbourne, neonates are ventilated with the Dräger Babylog 8000 ventilator using assist control and VG modes. Assist control is used because in this mode each of the infant's inspirations can trigger an inflation. A large screen on each ventilator shows flow, volume and pressure waves. We observed occasional wide fluctuations in the PIP from one inflation to the next that sometimes exceeded the manufacturer's limit of $3 \mathrm{~cm} \mathrm{H}_{2} \mathrm{O}$ from one inflation to the next. While investigating these changes in PIP we were informed by the manufacturers that the VG program controls the PIP independently for triggered and untriggered inflations and if the change in PIP from one inflation to the next exceeded $3 \mathrm{~cm}$ $\mathrm{H}_{2} \mathrm{O}$ this was probably owing to a change from a triggered to an untriggered inflation.

For triggered inflations the PIP chosen by the ventilator for each inflation relates to the PIP used for the previous triggered inflation, even if that occurred many inflations before. Similarly, the PIP for untriggered inflations relates to the PIP for the previous untriggered inflation. There is no time limit on the ventilator's memory for the PIP for the previous triggered or untriggered inflations. This independent control of PIP for the two types of inflation is important because when an infant inspires, contributes to the $\mathrm{V}_{\mathrm{Te}}$ and triggers an inflation, a lower PIP would be appropriate to assist the infant and deliver the set $V_{T e}$. Conversely, during inflations where the infant is apnoeic and not contributing to the $\mathrm{V}_{\mathrm{Te}}$, the inflation is not triggered and the $\mathrm{V}_{\mathrm{Te}}$ is dependent on the PIP. This means that triggered and untriggered inflations may have very different PIPs even if they are adjacent and might vary by more than $3 \mathrm{~cm} \mathrm{H}_{2} \mathrm{O}$.

This study aimed at investigating the effects of the infant's spontaneous breathing efforts and triggered or untriggered inflations on PIP and $\mathrm{V}_{\mathrm{Te}}$.

\section{METHODS}

These data were collected as part of an audit of neonatal ventilation at the Royal Women's Hospital, Melbourne. The research and ethics 


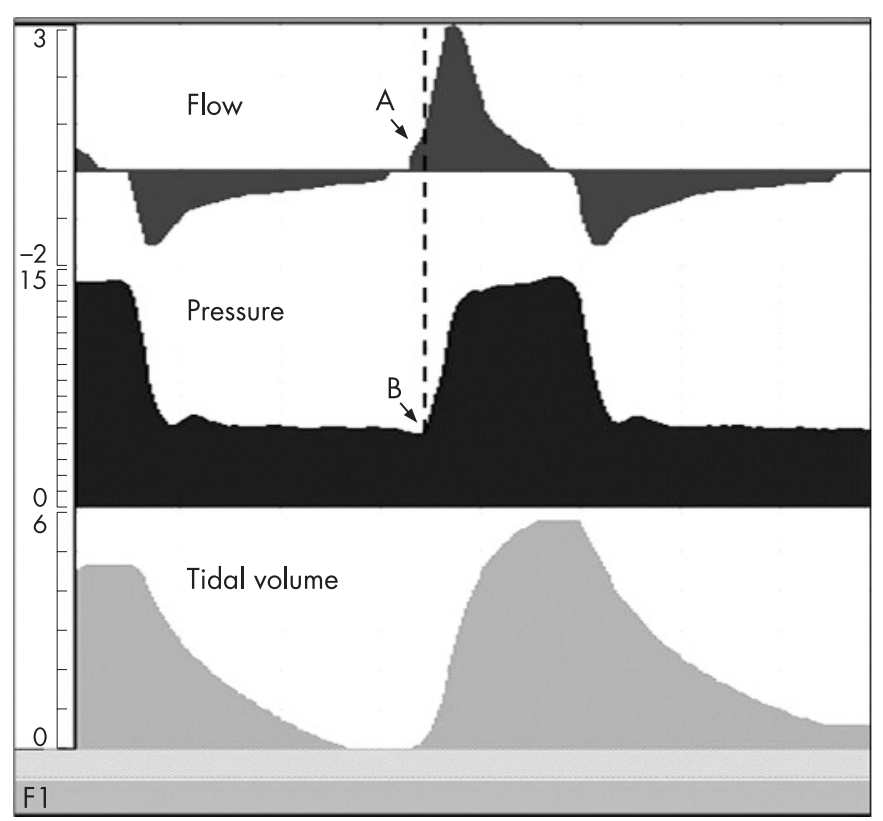

Figure 1 Illustration of the way in which triggered inflation was recognised for this study. The vertical dashed line shows the onset of the inflation pressure. Arrow $A$ indicates the inspiratory flow starting just before the onset of inflation. Arrow $B$ points to a small dip in the pressure wave just before the onset of inflation and coinciding with the onset of inspiratory flow.

committees agreed this could be done with verbal parental consent, as there was no interference with the infant or ventilator. A convenience sample of clinically stable infants was studied if the infant was not sedated or muscle relaxed, weighed $>500$ g, was $<38$ weeks' gestation and was ventilated with the Dräger Babylog 8000 using VG, assist-control (synchronous intermittent positive pressure ventilation) mode. Infants were not studied if they had a major congenital abnormality, periventricular leucomalacia or seizures. They were also excluded if there was an endotracheal tube leak $>60 \%$ of the inspiratory tidal volume because the VG mode becomes inaccurate above this level. Following local protocols infants were started with a set $V_{\mathrm{Te}}$ of $5 \mathrm{ml} / \mathrm{kg}$, inspiratory time of 0.3 seconds, rate $\sim 60 /$ minute, maximum PIP $30 \mathrm{~cm} \mathrm{H}_{2} \mathrm{O}$, positive end expiratory pressure (PEEP) $5 \mathrm{~cm} \mathrm{H}_{2} \mathrm{O}$, circuit flow $8 \mathrm{l} / \mathrm{min}$ and maximum trigger sensitivity. Where possible the $\mathrm{PaCO}_{2}$ was maintained between 5 and $8 \mathrm{kPa}(38-60 \mathrm{~mm} \mathrm{Hg}$ ) by adjusting the set $\mathrm{V}_{\mathrm{Te}}$. Flow and pressure waves were recorded from the ventilator analogue outputs at $200 \mathrm{~Hz}$ using the Spectra program (Grove Medical Ltd, London, UK). The flow wave was integrated to tidal volume.

Another study using these recordings has been reported. ${ }^{7}$ Basic demographic information and ventilator settings were recorded at the start of each study. Each study was timed to coincide with routine blood gas analysis that was used to establish adequacy of ventilation and calibrate the transcutaneous blood gas monitor. Infants were not handled during the 30 -minute recording and no changes were made to ventilator settings during this time. Simultaneous video recording was used to identify 10-minute epochs for analysis when the infant was not crying or moving.

The flow, volume and pressure waveforms were examined and analysed for each inflation both manually and using a Labview 5.0 (National Instruments, Austin, USA) program, designed by one of the authors. ${ }^{13}$ To analyse triggered and untriggered inflations separately inflations were identified as triggered if: (a) inspiratory gas flow preceded the start of the increase in inflating pressure; $(b)$ this coincided with a small dip in the pressure wave and $(c)$ the interval between inflations was less than that set on the ventilator (fig 1).

Normally distributed data were compared using the Student $t$ test and presented as mean and standard deviation. Nonparametric data were compared using Mann-Whitney U analysis and presented as median and range.

\section{RESULTS}

Ten infants ventilated through an endotracheal tube were studied for 30 minutes each, and 10 minutes of movement-free recording selected from each study. About 600 consecutive inflations were analysed in detail for each infant. In total 6540 inflations were analysed. Of these, 4052 (62\%) were triggered and 2488 (38\%) not triggered. Figure 2 illustrates the appearance of triggered and untriggered inflations.

The infants' characteristics, median (range), were: gestational age 28 (24-37) weeks, weight $1275 \mathrm{~g}$ (630-3110 g), day of life when studied $3(1-24)$, set $\mathrm{V}_{\mathrm{Te}}$ at the time of the study 3.85 $(2.8-4.7) \mathrm{ml} / \mathrm{kg}$ and fractional inspired oxygen $0.28(0.21-0.80)$. All had acceptable blood gases and maintained adequate ventilation and oxygenation throughout: mean (SD) $\mathrm{SpO}_{2} 96$ (3) \%, $\mathrm{TcCO}_{2} 6.2(1.3) \mathrm{kPa}(48(10) \mathrm{mm} \mathrm{Hg})$ and heart rate 142 (14) beats/min.

\section{Effect of triggered and untriggered inflations on peak inflating pressure}

Overall triggered inflations $(n=4053)$ had a lower PIP at 12.9 (4.9) $\mathrm{cm} \mathrm{H}_{2} \mathrm{O}$ than untriggered inflations $(\mathrm{n}=2488)$ at 17 (3.5) $\mathrm{cm} \mathrm{H} \mathrm{H}_{2} \mathrm{O}(\mathrm{p}<0.001)$. The mean $(95 \% \mathrm{CI})$ PIP for triggered inflations was significantly lower than for untriggered inflations by 4.1 (3.9 to 4.3$) \mathrm{cm} \mathrm{H}_{2} \mathrm{O}$. When triggered inflations were immediately followed by an untriggered inflation $(n=838)$ the peak inflating pressure increased by a mean (SD) of $5.1(6.7) \mathrm{cm}$ $\mathrm{H}_{2} \mathrm{O}$. When untriggered inflations $(\mathrm{n}=839)$ were followed by a triggered inflation the PIP fell by 4.8 (6.7) $\mathrm{cm} \mathrm{H}_{2} \mathrm{O}$.

Between adjacent triggered inflations $(n=3209)$ the change in PIP was $0.11(1.50) \mathrm{cm} \mathrm{H}_{2} \mathrm{O}$ and between adjacent untriggered inflations $(n=1644)$ it was $0.06(1.53) \mathrm{cm} \mathrm{H}_{2} \mathrm{O}$. Therefore pressure changes between inflations of the same type were less than $3.0 \mathrm{~cm} \mathrm{H}_{2} \mathrm{O}$ for $97.7 \%$ of the time.

\section{Effect of triggered and untriggered inflations on expired tidal volume}

Despite the differences in PIP between the two types of inflations there was no significant difference between the delivered $\mathrm{V}_{\mathrm{Te}}$ as a percentage of the set $\mathrm{V}_{\mathrm{Te}}$ : triggered $103 \%$ and untriggered $101 \%$.

When triggered inflations were immediately followed by an untriggered inflation $(n=838)$ and the PIP increased the $V_{T e}$ rose by $0.23(2.06) \mathrm{ml} / \mathrm{kg}$. When untriggered inflations were followed by a triggered inflation $(n=839)$ the $\mathrm{V}_{T e}$ fell by 0.26 (2.19) $\mathrm{ml} / \mathrm{kg}$.

The change in $\mathrm{V}_{\mathrm{Te}}$ between adjacent triggered inflations $(\mathrm{n}=3209)$ was $0.04 \quad(1.22) \mathrm{ml} / \mathrm{kg}$ and between adjacent untriggered inflations $(\mathrm{n}=1644)$ it was $0.09(1.41) \mathrm{ml} / \mathrm{kg}$.

The set maximum PIP of $30 \mathrm{~cm} \mathrm{H}_{2} \mathrm{O}$ might have limited some of the inflating pressures. However, only $0.2 \%$ of the inflating pressures reached the set PIP. 

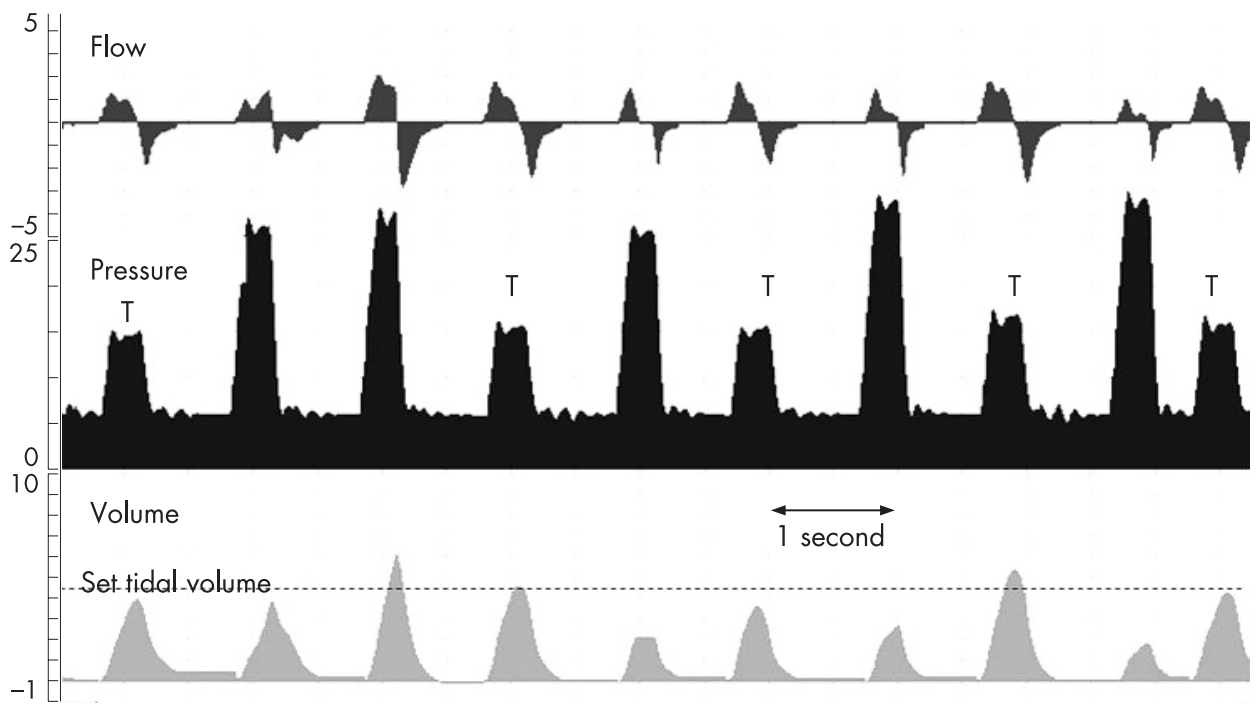

Figure 2 A recording of volume guarantee ventilation, running from left to right, showing 10 consecutive inflations. The inspiratory and expiratory flow curves are at the top, inflating pressure in the middle and tidal volume at the bottom. Five inflations marked with a T are triggered and the other five are untriggered. The dotted line represents the preset expired tidal volume of $4.2 \mathrm{ml}$, selected by the clinician. The first triggered inflation marked ' $T$ ' (first inflation in the figure) delivers a PIP of $15 \mathrm{~cm} \mathrm{H}_{2} \mathrm{O}$ and a $\mathrm{V}_{\mathrm{Te}}$ of $3.5 \mathrm{ml}$, which is under the set $\mathrm{V}_{\mathrm{Te}}$. In the second triggered inflation (inflation 4) the PIP has increased to $16 \mathrm{~cm} \mathrm{H} 0$, to compensate for the previously low $\mathrm{V}_{\mathrm{Te}}$ and the $\mathrm{V}_{\mathrm{Te}}$ delivered was marginally above the set $\mathrm{V}_{\mathrm{Te}}$. The third triggered inflation (inflation 6) has a similar PIP but only achieves a $\mathrm{V}_{\mathrm{Te}}$ of $3.8 \mathrm{ml}$. Because of this low tidal volume the next triggered inflation (inflation 8) has an increased PIP to $17 \mathrm{~cm} \mathrm{H}_{2} \mathrm{O}$, however this delivers a $\mathrm{V}_{\mathrm{Te}}$ of $5.2 \mathrm{ml}$, slightly above the set value and so the last triggered inflation (inflation 10) uses a marginally lower PIP to reduce the $\mathrm{V}_{\mathrm{Te}}$. Inflations $2,3,5,7,9$ are all untriggered inflations. They have a PIP of around $27 \mathrm{~cm} \mathrm{H}_{2} \mathrm{O}$. These are much higher than the triggered inflations. The PIP for these untriggered inflations varies slightly to try and ensure the set $\mathrm{V}_{\mathrm{Te}}$. The $\mathrm{V}_{\mathrm{Te}}$ delivered by the untriggered inflations can be seen to be very similar to those with triggered inflations, even though the PIP was much higher.

\section{DISCUSSION}

We report a detailed analysis of changes in PIP and expired tidal volume for individual triggered and untriggered inflations during VG ventilation with the Dräger Babylog 8000 ventilator. This has not been possible in other studies of volume ventilation where the data have not been acquired in detail for individual inflations but have been averaged over varying periods. ${ }^{6} 1114$

Volume-targeted modes of neonatal ventilation are used to reduce volutrauma and associated ventilator-induced lung injury that has been linked to the development of bronchopulmonary dysplasia. ${ }^{2}$ A meta-analysis comparing volume-targeted ventilation with traditional time-cycled, pressure-limited modes has shown reductions in the duration of ventilation, rates of pneumothorax and severe intraventricular haemorrhage, and shows a trend towards a reduction in the incidence of bronchopulmonary dysplasia (relative risk $=0.34(95 \%$ CI 0.11 to 1.05$)) .{ }^{15}$

When triggered and untriggered inflations were analysed separately (ie, the pressure for a triggered inflation compared with an adjacent triggered inflation, and similarly for untriggered inflations), the differences were within the manufacturer's $3 \mathrm{~cm} \mathrm{H} \mathrm{H}_{2} \mathrm{O}$ limit for both types for $97 \%$ of the time.

\section{What is already known on this topic}

- Volume guarantee ventilation delivered by the Dräger Babylog 8000 plus ventilator is a pressure-limited, time-cycled, triggered mode that targets a set expired tidal volume by altering the peak inflating pressure for each inflation.

- These pressure changes should not exceed $3 \mathrm{~cm} \mathrm{H}_{2} \mathrm{O}$ between inflations according to the manufacturers.

- The effect of triggered and untriggered inflations on the inflation pressures and tidal volumes has not been reported.
However, pressure fluctuations above $3 \mathrm{~cm} \mathrm{H}_{2} \mathrm{O}$ occurred between consecutive inflations when the inflations changed between triggered and untriggered modes. Triggered inflations, where the infant contributed to the tidal volume, were delivered with a PIP about $4 \mathrm{~cm} \mathrm{H} \mathrm{H}_{2} \mathrm{O}$ lower than untriggered inflations.

The difference in PIP between triggered and untriggered inflations is due to the presence or absence of infant inspiratory effort. During an untriggered inflation the infant is not inspiring and so the ventilator pressure has to be sufficient to provide the set tidal volume. During a triggered inflation the infant is inspiring and contributing to the tidal volume. The VG program adjusts the peak pressure to ensure a set expired tidal volume and so the pressure needed to ensure the tidal volume with a triggered inflation is lower than with an untriggered inflation. This change in peak pressure inflation does not occur with timecycled, pressure-limited ventilation in assist-control mode.

Our own observations have shown that pressure-limited ventilator modes which do not control the tidal volume deliver a fixed PIP independent of the infant's respiratory effort. This results in very large changes in tidal volume as the infant varies their spontaneous tidal volume or the lung compliance changes.

In this study only $62 \%$ of the inflations were triggered because the set ventilator rate of $60 / \mathrm{min}$ was close to the infant's spontaneous respiratory rate; this reduced the infant's ability to trigger the ventilator because a mandatory, or back-up inflation, was delivered before the infant had time to inspire. Our recent experience has been that with a ventilator rate lower than $60 / \mathrm{min}$ the proportion of triggered inflations increases. This is likely to improve the overall effect of VG ventilation when the baby is breathing spontaneously and triggering inflations.

The information in this study is specific to the Dräger Babylog 8000 plus ventilator. Other neonatal ventilators, with other methods of controlling tidal volume do not have the same 


\section{What this study adds}

- Between inflations of the same type (triggered or untriggered) the change in peak pressure between consecutive inflations in less than $3 \mathrm{~cm} \mathrm{H} O$.

-When a triggered inflation is immediately adjacent to an untriggered inflation the change in peak pressure can be around $5 \mathrm{~cm} \mathrm{H} O$.

- Although triggered inflations have a peak pressure $4 \mathrm{~cm} \mathrm{H} \mathrm{H}_{2} \mathrm{O}$ lower than untriggered inflations this makes no difference to the expired tidal volumes.

control algorithms for triggered and untriggered modes, nor do they all target the expiratory tidal volume.

\section{CONCLUSION}

During VG ventilation with the Dräger Babylog 8000 the PIP was $4 \mathrm{~cm} \mathrm{H}_{2} \mathrm{O}$ lower during triggered inflations than untriggered inflations, although the expired tidal volumes were similar. The fluctuations in inflating pressures during VG ventilation are an integral part of providing consistent expiratory tidal volumes for ventilated infants with variable inspiratory effort.

Acknowledgements: Peter Dargaville and Naomi McCallion were holders of a Murdoch Children's Research Institute Senior Research Fellowship and a Royal Women's Hospital Research Fellowship, respectively.

Competing interests: None.

\section{REFERENCES}

1. Dreyfuss D, Basset G, Soler P, et al. Intermittent positive-pressure hyperventilation with high inflation pressures produces pulmonary microvascular injury in rats. Am Rev Respir Dis 1985;132:880-4.

2. Coalson JJ, Winter VT, Siler-Khodr T, et al. Neonatal chronic lung disease in extremely immature baboons. Am J Respir Crit Care Med 1999:160:1333-46.

3. Keszler M, Abubakar K. Volume guarantee: stability of tidal volume and incidence of hypocarbia. Pediatr Pulmonol 2004;38:240-5.

4. Brochard L, Roudot-Thoraval F, Roupie E, et al. Tidal volume reduction for prevention of ventilator-induced lung injury in acute respiratory distress syndrome. The Multicenter Trial Group on Tidal Volume reduction in ARDS. Am J Respir Crit Care Med 1998;158:1831-8

5. Lista G, Castoldi F, Fontana $P$, et al. Lung inflammation in preterm infants with respiratory distress syndrome: effects of ventilation with different tidal volumes. Pediatr Pulmonol 2006;41:357-63.

6. Abubakar K, Keszler M. Effect of volume guarantee combined with assist/control vs synchronized intermittent mandatory ventilation. J Perinatol 2005;25:638-42.

7. Singh J, Sinha SK, Clarke $P$, et al. Mechanical ventilation of very low birth weight infants: is volume or pressure a better target variable? J Pediatr 2006:149:308-13.

8. Davis PG, Morley CJ. Volume control: a logical solution to volutrauma? J Pediatr 2006;149:290-1.

9. Lista G, Colnaghi M, Castoldi F, et al. Impact of targeted-volume ventilation on lung inflammatory response in preterm infants with respiratory distress syndrome (RDS). Pediatr Pulmonol 2004;37:510-4.

10. McCallion N, Lau R, Dargaville PA, et al. Volume guarantee ventilation, interrupted expiration, and expiratory braking. Arch Dis Child 2005;90:865-70.

11. Cheema IU, Ahluwalia JS. Feasibility of tidal volume-guided ventilation in newborn infants: a randomised, crossover trial using the volume guarantee modality. Pediatrics 2001;107:1323-8.

12. Herrera CM, Gerhardt T, Claure N, et al. Effects of volume-guaranteed synchronized intermittent mandatory ventilation in preterm infants recovering from respiratory failure. Pediatrics 2002;110:529-33.

13. Dargaville $\mathbf{P}, \mathrm{McC}$ Callion N, Morley CJ. Analysis of complex respiratory signals using a novel interactive breath analysis program [abstract]. Pediatr Res 2003;53:2669A

14. Sinha SK, Nicks JJ, Donn SM. Graphic analysis of pulmonary mechanics in neonates receiving assisted ventilation. Arch Dis Child 1996;75:F213-8.

15. McCallion N, Davis PG, Morley CJ. Volume-targeted versus pressure limited ventilation in the neonate. Cochrane Database Syst Rev 2005:20:CD003666.

\section{Let us assist you in teaching the next generation}

Figures from all articles on our website can be downloaded as a PowerPoint slide. This feature is ideal for teaching and saves you valuable time. Just click on the image you need and choose the "PowerPoint Slide for Teaching" option. Save the slide to your hard drive and it is ready to go. This innovative function is an important aid to any clinician, and is completely free to subscribers. (Usual copyright conditions apply.) 